\section{RIDGE+: An improved biased regression routine}

\section{ANDREW J. BUSH \\ Memphis State University, Memphis, Tennessee 38152}

The ridge regression program, RIDGE, offered by Bush (1980) for dealing with prediction problems in the presence of highly multicollinear data, has been replaced by an updated version, RIDGE+. The new version produces the ordinary least squares (OLS), component regression, and ridge regression solutions previously addressed by RIDGE and, in addition, yields a class of solutions based upon Marquardt's (1970) generalized inverse strategy.

As computed by RIDGE+, the latter solutions are based upon an integral reduced rank model in which predictor parameter estimates are established stagewise from the forward regression of the criterion variable on predictor principal components that have been ordered for entry by decreasing validities (cf. Greenberg, 1975; Hocking, Speed, \& Lynn, 1976; Massy, 1965). Given the apparent role of component validity concentration in determining the relative utility of different classes of biased solutions (cf. Darlington, 1978), this approach constitutes a particularly relevant strategy for generating competitive alternative regression weight configurations that may be synthesized with ridge regression estimates for best results under a variety of conditions.

In general, the output produced by the original program version has been retained. However, doubleprecision arithmetic has been employed extensively to replace the single-precision calculations performed earlier. Since the original version has been thoroughly described (cf. Bush, 1980), only those features constituting a revision will be addressed in detail here.

Description. Written in FORTRAN IV, RIDGE+ accesses subroutines RCALC, HOW (cf. Cooley \& Lohnes, 1971), CHOLESKY, INVCHO, INVMUL, CALBETA, COVAR, REOUT, VPRNT, SUMMAR, and PUMP in the same order as it predecessor. However, unlike their initial counterparts, VPRNT, SUMMAR, and PUMP have been rewritten to conform to computer environments that require that disk files used for both input and output maintain identical read and write formats. Similarly, Subroutine HOW has been altered to remove an equivalence statement found to create problems at some installations.

Most important, additions have been made to HOW that allow (1) ordering of principal components by decreasing validities, (2) computation of reduced rank beta estimates drawn from increasingly greater numbers of included components, (3) computation of corresponding raw weights if raw data are available, (4) retention of stagewise squared multiple correlations (SMCs), and (5) creation of ordered output on F:10 for input to a plotter routine

Input. The input conventions described for the original program have not been altered. For a complete description of the nine job cards needed to execute the program on raw or correlational input, the reader is referred to Bush (1980, p. 73).

Output. In addition to the output provided by the initial program version, RIDGE+ now displays (1) accumulated beta estimates over decreasing component validities, (2) corresponding accumulated raw weight and intercept estimates when appropriate, and (3) increasing values for SMCs over the progressively greater number of incorporated components. Unlike the original version, RIDGE+ no longer displays the inverse of the predictor correlation matrix but does provide a complete display of OLS, component, and generalized inverse solutions, along with summary ridge regression output whenever summary output is requested.

Restrictions. The data matrix may not have more than 49 predictors. Since most problems have far fewer, this is not a major restriction. At present, the total number of observations is limited to 999 . This limit can be easily increased by altering the appropriate input format statement from 13 to 14 . Since raw data are not stored internally, no other changes are required for reading larger data sets. Although only integral reduced rank information is presented, fractional estimates (cf. Hocking et al., 1976; Marquardt, 1970) can be obtained easily from the output using a strategy delineated by Bush (Note 1).

Computer and Language. The program is written in standard FORTRAN IV and has been thoroughly tested on the Memphis State University Xerox Sigma 9 computer. For ease of conversion, all data reference numbers are identified and assigned early in the source. The program is well documented with comments and executes easily in timesharing modes with access to $25 \mathrm{~K}$ words or more. To reduce conversion problems, suggestions from programmers at other computer installations have been followed in preparing the code.

Availability. The listing of the source program, sample input, output, and complete user documentation are available at a charge of $\$ 5$ to cover costs from the author. Andrew J. Bush, Foundations of Education, Memphis State University, Memphis Tennessee 38152.

\section{REFERENCE NOTE}

1. Bush, A. J. Improving estimation through joint application of biased regression techniques. Paper presented at the annual meeting of the American Educational Research Association, Los Angeles, April 1981. 


\section{REFERENCES}

Bush, A. J. Ridge: A program to perform ridge analysis. Behavior Research Methods \& Instrumentation, 1980, 12, 73-74.

Cooley, W. W., \& Lohnes, P. R. Multivariate data analysis. New York: Wiley, 1971.

Darlington, R. B. Reduced variance regression. Psychological Bulletin, 1978, 85, 1238-1255.

GreenberG, E. Minimum variance properties of principal component regression. Journal of the American Statistical Association, 1975, 70, 194-197.
Hocking, R. R., Speed, F. M., \& LynN, M. J. A class of biased estimators in linear regression. Technometrics, 1976, 18, 425-437.

Marquandt, D. W. Generalized inverse, ridge regression, biased linear estimation, and nonlinear estimation. Technometrics, 1970, 12, 591-612.

Massy, W. F. Principal components regression in exploratory statistical research. Journal of the American Statistical Association, 1965, 60, 234-256.

(Accepted for publication May 21, 1981.) 